\title{
Hardy-rose Breeding at the Morden Research Station
}

Roses, an important nursery crop throughout the world, are one of the most popular flowering shrubs grown for landscaping. The hybrid tea is the most popular type of rose. However, hybrid teas do not consistently survive in climates colder than hardiness zone 5, an area encompassing most of Canada and the midnorthern United States. In the Canadian prairies, temperatures of -30 to $-40 \mathrm{C}$ are not uncommon. Additionally, because most roses are budded onto a rootstock, a problem unique to cold climates occurs. If low temperatures injure the budded cultivar, the rootstock continues to grow and often outcompetes the desirable cultivar. Nonetheless, in recent years, interest and market demand for hardy roses has grown, as evidenced by the growing trade and increased public and media requests for information and plants.

The primary objective of the breeding program at the Agriculture Canada Research Station, Morden, Manitoba (RSM), is to develop low-growing, everblooming, diseaseresistant, and aesthetically pleasing roses that can survive the cold winter and dry summer conditions of the Canadian prairies. To achieve this goal, several species have been used as a source of hardiness and adaptability for prairie conditions. These specieswere hybridized with hybrid teas and floribundas to combine the desired characteristics.

A native prairie species, Rosa arkansana Porter, was used extensively in the breeding program because of its tolerance to hot, dry summers and cold winters. It is a low-growing plant often found along roadsides, in ditches, and even as a weed in farmers' fields. Plants of $R$. arkansona bloom on current-season and older wood, so flower production continues throughout the growing season, unlike many other species that bloom only in early summer. Rosa arkansana is a tetraploid, which makes it easier to hybridize with other tetraploid tender roses. 'Assiniboine' rose ('Donald Prior' $\times R$. arkansana) is an example of a first-generation hybrid developed in the breeding program. This cultivar was introduced in 1962 as a new type of hardy rose for the Canadian prairies. Plant growth is bushy, with semidouble, purplish-red flowers formed mainly in June, then sporadically throughout the growing season. 'Assiniboine' is susceptible to rust (Phragmidium sp.), as is its parent, $R$. arkansana. In

Received for publication 30 July 1992. Accepted for publication 27 Aug. 1992. The cost of publishing this paper was defrayed in part by the payment of page charges. Under postal regulations, this paper therefore must be hereby marked advertisement solely to indicate this fact.

Front cover: 'Winnipeg Parks' rose (see p. 1140). cultivars developed later, however, resistance to the disease was improved by crossing to more resistant parents.

'Assiniboine' was backcrossed to R. arkansana to improve hardiness, then crossed to more tender parents to increase petal count and flower quality (Fig. 1). 'Adelaide Hoodless' (1973) and 'Morden Ruby' (1977) were developed from these crosses. 'Morden Ruby' is unique because it is a solid-red-flowered mutation from a mottled selection. Occasionally, the flowers revert back to the mottled form. 'Cuthbert Grant' (1967), 'Morden Amorette' (1977), and 'Morden Cardinette' (1979) (Marshall and Collicutt, 1985) were developed through more complex hybridizations (Fig. 1). 'Morden Amorette' and 'Morden Cardinette' wereselected as single dwarf plants in tall-growing seedling families.

'Morden Cardinette' was used in the development of three recent cultivars: 'Winnipeg Parks' (see p. 1140), 'Morden Fireglow'
(Collicutt, 1991), and 'Prairie Joy' (Collicutt, 1991) (Fig. 1).

'Morden Centennial' (1980), 'Morden Cardinette' (1980), 'Morden Blush' (1988), and 'Prairie Joy' (1991) (Fig. 1) have the shrub 'Prairie Princess' in their pedigree. Rosa laxa Retz. and R. spinosissima L., two tetraploid species, were incorporated into the breeding program through 'Prairie Princess' ['Carrousel' $\times$ ('Morning Stars' $\times$ 'Suzanne')]. 'Suzanne' is a second-generation seedling from $R$. laxa $\times R$. spinosissima (Haring, 1986).

In 1980 RSM K1 and RSM K5 were released as a source of germplasm for hardiness and disease resistance (Marshall, 1980). These two hybrids were selected from a seedling population of $R$. rugosa 'Alba' $\times\{[R$. arkansana'J.W.Fargo' $\times($ 'DonaldPrior' $\times$ R.arkansana)] $\times$ mixed $R$. arkunsana hybrids $\}$. Both are fertile tetraploids and exhibit the rough foliage of $R$. rugosa Thunb. Although subsequent generations of these hybrids did exhibit good hardiness, inheritance of blackspot resistance appeared intermediate to poor.

Three anthocyanin pigments-cyanidin, peonidin, and pelargonidin-are responsible for the various shades of red, pink, and lavender of rose flowers (Arisumi, 1963; Harborne, 1961; Yokoi, 1974). These pigments occur either as 3,5-diglucosides or 3-glucosides of

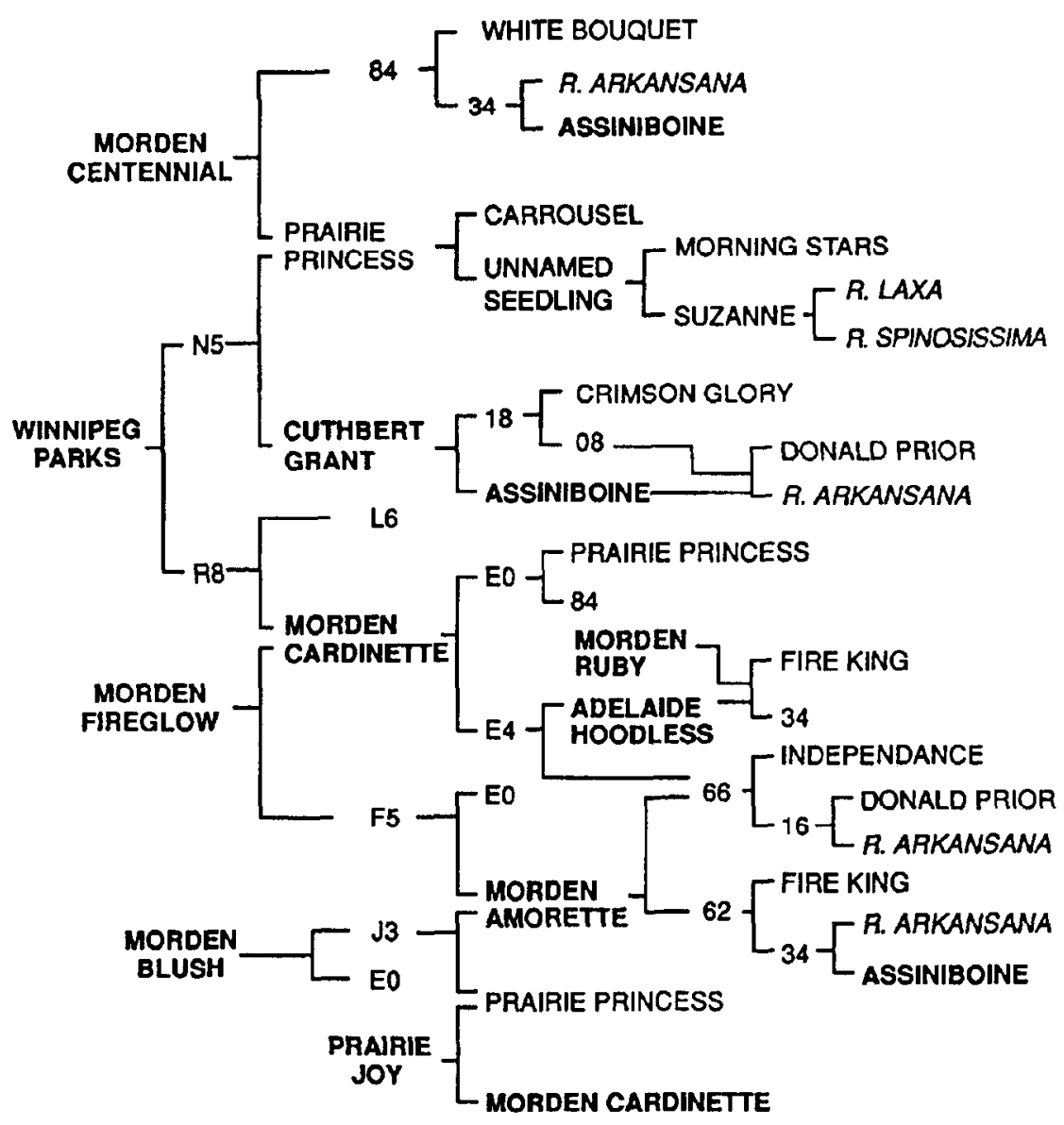

Fig. 1. Genealogy of Parkland roses. (Species are in italics; Parkland roses are in boldface, letters/ numbers are unnamed seedling codes.) 
the respective anthocyanins. The results of inheritance studies of these pigments (Marshall et al., 1983) were used in breeding for scarletred and white flowers. 'Morden Fireglow' was developed through the selection of its parents on the basis of a chromatographic determination of anthocyanin pigment content (Collicutt, 1991; Marshall, 1975). This cultivar combines winter hardiness with a unique scarlet-red flower, a color rarely seen in hardy roses. 'Morden Fireglow' has a high level of pelargonin, the pigment responsible for the scarlet tones in the flower. Likewise, 'Morden Blush' (Collicutt, 1989), which has an ivory flower and low levels of anthocyanins, was developed using a similar approach.

The Parkland Rose Series does not fit into existing categories and is best described as intermediate between large hardy shrubs and tender floribunda types. They bloom more freely throughout the growing season than do the older, large shrub types but are hardier than floribundas and hybrid teas. These cultivars can be grown in the landscape as specimen plants or in mass plantings.

The Parkland roses are propagated by softwood stem cuttings and grown on their own roots. This method of growing eliminates suckering problems that are common with budded or grafted roses grown in cold climates. Optimum rooting occurs when cuttings are made in spring to early summer, treated with 3000 to $7000 \mathrm{ppm}$ indole-butyric acid, and rooted under intermittent mist or fog (Collicutt, 1981). Tissue culture can also be used. Although the roots are hardy in Agriculture
Canada zone 3 (Ouellet and Sherk, 1967), varying amounts of stem die-back may occur depending on the climatic conditions and amount of snowfall. This growth characteristic actually results in a smaller plant habit, a desirable trait for many landscape situations. Attractive bushes with abundant flowers will develop during the growing season even if plants have died to near ground level during the winter.

Future directions of the breeding program will include the development of a cold-tolerance screening procedure using a programmable freezer to decrease the time required for hardiness evaluation outdoors. In addition, development of hardy cultivars with yellow and white flowers is a major objective in the program. Breeding for these colors is more difficult than for red or pink flowers due to their recessive inheritance. Rose breeding is a long-term project, combining the desired flower color and quality from more tender roses with the hardiness required under prairie growing conditions. Ten to 15 years are often required from an initial cross pollination until a cultivar is available commercially.

Rose cultivars developed by Agriculture Canada are introduced in Canada through the Canadian Ornamental Plant Foundation (652 Aberdeen Ave., North Bay, ON P1B 7H9, Canada). The nursery industry generally requires 2 to 3 years to produce enough plants for the retail market. Requests in the United States should be directed to Bailey Nurseries, 1325 Bailey Rd., St. Paul, MN 55119.

\section{Literature Cited}

Arisumi, K. 1963. Studies on the flower colours in Rosa with special reference to the biochemical and genetic analyses and to the application of those results to the practical breeding (in Japanese, English summary). 1. Sci. Bul., Fat. Agr., Kyushu Univ. 20(2):131-149.

Collicutt, L.M. 1981. Propagation of the Parkland Rose Series by leaf-bud cuttings. MS Thesis, Univ. of Manitoba, Winnipeg, Canada.

Collicutt, L.M. 1989. Morden Blush Rose. Can. J. Plant Sci. 69:623-624.

Collicutt, L.M. 1991. 'Morden Fireglow' rose. HortScience 26:318-319.

Harbome, J.B. 1961. The anthocyanins of roses. Occurrence of peonin. Experimentia XVII:7273.

Haring, P. (ed.). 1986. Modern roses 9. Amer. Rose Sot., Shreveport, La.

Marshall, H.H. 1975. New genetic sources of peonin and a new combination of anthocyanins in Rosa. J. Amer. Soc. Hort. Sci. 100:336-338.

Marshall, H.H. 1980. RSM K1 and RSM K5 rose germplasm. HortScience 15:205-206.

Marshall, H.H., C.G. Campbell, and L.M. Collicutt. 1983. Breeding for anthocyanin colors in Rosa. Euphytica 32:205-216.

Marshall, H.H. and L.M. Collicutt. 1985. 'Morden Amorette' and 'Morden Cardinette' roses. HortScience 20:305-306

Ouellet, C.E. and L.C. Sherk. 1967. Woody ornamental plant zonation. III. Suitability map for the probable winter survival of ornamental trees and shrubs. Can. J. Plant Sci. 47:3513-3568.

Yokoi, M. 1974. Colour and pigment distribution in ornamental plants. V. Anthocyanin distribution in rose cultivars. Tech. Bul., Fat. Hort., Chiba Univ. 22:13-24. Hort. Abstr. 1976. 46(2):137, 139. no. 1470 .

LYNN COLliCUTT Agriculture Canada Research Station P.O. Box 3001 Morden, Man. ROG 1J0, Canada 